\title{
EUTOMIA
}

Revista de Literatura e Linguística

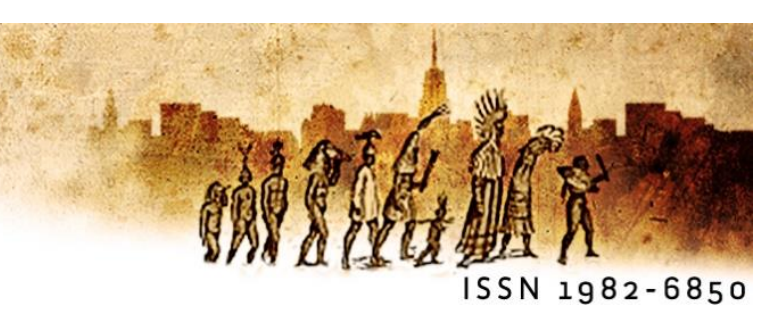

\section{Literatura e Re-existência: Possibilidades do fazer literário como instrumento de ação e mudança social}

\author{
Allinne Silva Santos' (UESB) \\ Adriana Maria de Abreu Barbosaii (UESB)
}

\begin{abstract}
Resumo: A fim de compreender as alternativas que as mulheres escritoras brasileiras têm encontrado para que seus escritos literários sejam lidos, alcancem públicos diversos, identificando suas estratégias ao realizar e produzir uma literatura reflexiva, lançamos o nosso olhar para 3 movimentos do fazer literário neste estudo: a antologia literária e fotográfica Profundanças. A coalizão de mulheres escritoras do Movimento Respeita!. E, por último o fazer poético da escritora Ângela Toledo. Para tais análises utilizaremos a $A C D$, a Crítica Feminista, tratando também sobre às "escritas de si".

Palavras-chave: Mulheres; Literatura; Discurso e Re-existência.
\end{abstract}

\begin{abstract}
Abstrac: In order to understand the alternatives that Brazilian women writers have found for their literary writings to be read, reach diverse audiences, identifying their strategies when performing and producing a reflective literature, we cast our gaze to 3 movements of literary making in this study: the literary and photographic anthology Profundanças. The coalition of women writers of the Respect Movement!. And finally, the poetic making of the writer Angela Toledo. For such analyses we will use the ACD, the Feminist Criticism, also dealing with the "writings of themselves".

Key Works: Women; Literature; Speech and Re-existence.
\end{abstract}

\section{Introdução}

Nos interessa observar de perto como as mulheres escritoras brasileiras estão se apropriando do território da literatura deste século XXI, como instrumento de resistência, ou seja, fazem uso da linguagem poética para refletir o seu tempo, tempo este de tantas incertezas e vulnerabilidades, tempos de 
grandes desigualdades, tempos em que ainda questionamos como são as mulheres, como se constroem socialmente, como sobrevivem ao patriarcado e modos de ruptura. A Re-existência se inscreve nos movimentos de mulheres que coletivamente tomam a linguagem, em suas diversas maneiras de realização, para se impor contra o sistema hegemônico de dominação sociocultural e política.

O conceito de Re-existência que aqui trabalhamos é o que vem sendo construído pelo ativismo social das minorias políticas em seus discursos de resistir pela arte, de insistir em novas maneiras de viver e se colocar no mundo, assim como nos elucida Mariane Pimentel em seu texto $A$ arte de resistir ou a reexistência da arte (2012), onde pensa os novos espaços de existências, as novas maneiras de ser e existir tendo a arte como instrumento de abertura para a realização que às minorias sociais almejam. Como também BOSI em Narrativas de Resistencia (1996) fala sobre o ato de Resistir sendo o insistir, contrário de desistir. Afirmando que Resistir é um "conceito originariamente ético e não estético". De forma mais abrangente, ao longo do texto, Bosi fala sobre os valores sociais que movem o autor em sua narrativa, funcionando como força catalisadora

A translação de sentido da esfera ética para a estética é possível, e já deu resultados notáveis, quando o narrador se põe a explorar uma força catalisadora da vida em sociedade: os seus valores. O homem de ação, o educador ou o político que interfere diretamente na trama social, julgando-a e, não raro, pelejando para alterá-la, só o faz enquanto é movido por valores. Estes, por seu turno, repelem e combatem os antivalores respectivos. O valor é objeto da intencionalidade da vontade, é a força propulsora das suas ações. O valor está no fim da ação, como seu objetivo; e está no começo dela enquanto é sua motivação. (BOSI, p.13,14. 1996)

Usar o termo Literatura e Re-existência para nós significa buscar outras maneiras de sobreviver a nossa realidade por meio da literatura, da arte e performance literária, do trabalho com a linguagem literária. Notamos que essa literatura intenta discutir gênero e para além do gênero e desse modo é uma literatura que dialoga com os feminismos como escolas de pensamento nos quais o binarismo homem e mulher aparece como algo a ser superado. 
Clarice Lispector, certa feita, numa entrevista ${ }^{1}$ disse que a literatura não mudava nada. No entanto este trabalho ousa contrapor Clarice por duas razões. A primeira é reconhecer a importância da literatura para vida acadêmica e também para vida não acadêmica. A segunda e mais relevante para nossos estudos é reconhecer que a autoria feminina que hoje abarca mulheres acadêmicas, não acadêmicas, trabalhadoras domésticas, jornalistas, professoras, etc., que a produção dessa literatura está inserida na disputa dos espaços discursivos e tonando possível, mudanças sociais por meio da linguagem literária, e, desta forma, transformando suas realidades, como nos Dalcastagnè (2012) afirma

[...] quando diferentes grupos sociais procuram se apropriar de seus recursos, a literatura brasileira é um território contestado. Muito além de estilos ou escolhas repertoriais, o que está em jogo é a possibilidade de dizer sobre si e sobre o mundo, e de se fazer visível dentro dele. Hoje, cada vez mais, autores e críticos se movimentam na cena literária em busca de espaço- e de poder, o poder de falar com legitimidade ou de legitimar aquele que fala. Daí os ruídos e o desconforto causados pela presença de novas vozes, vozes "não autorizadas"; pela abertura de novas abordagens e enquadramentos para pensar a literatura; ou, ainda, pelo debate da especificidade do literário, em relação a outros modos de discursos, e das questões éticas suscitadas por esta especificada. (DALCASTAGNĖ, 2012, p. 7)

Ao tomar para si este poder, que é o discurso, a linguagem sendo utilizada, moldada feito peça de argila, como pedaços de vidro tal qual mosaico, as mulheres escritoras buscam refazer a história pela ótica e perspectiva de suas próprias experiências, vivências, desafiando assim, a maneira canônica de se produzir poesia, literatura. Histórias contadas ao seu modo e a do tempo do qual fazem parte, modificando a realidade, estando sem ludibriar ou querer esconder sua passagem no mundo, imprimem na escrita as angústias e desejos numa linguagem rasurada, tendo-a como uma linguagem contestadora, que questiona o que está posto e dito (HALL, 1996). Como bem coloca Rosiska Darcy de Oliveira em Elogio a Diferença, acerca do movimento feminista e aqui entendemos a

\footnotetext{
${ }^{1}$ Entrevista realizada por Júlio Lerner com Clarice Lispector concedida a TV Cultura no ano de 1977. Podendo ser encontrada no Youtube, no canal TV Cultura Digital, através do

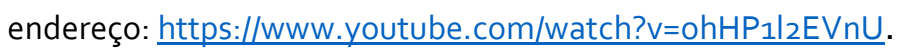


realidade de mulheres feministas escritoras que buscam incomodar, desconcertar, irritar.

O futuro do movimento é angustiar a sociedade, deparando-a com os problemas que, até agora, as mulheres tentaram resolver sozinhas. Transformar a neurose das mulheres em neurose social é o recurso terapêutico de que elas terão de lançar mão. (OLIVEIRA, 1983, p. 88)

Nos apoiamos, também, em Margareth Rago em seu A aventura de contarse (2013) para expressar esse fazer literário dessas mulheres escritoras, que rasuram a realidade com as suas experiências de vida, levando em consideração suas subjetividades, fazendo da linguagem seu grande instrumento de subversão e luta.

Parto da concepção de que a linguagem e o discurso são instrumentos fundamentais por meio dos quais as representações sociais são formuladas, veiculadas, assimiladas, e de que o real-social é construído discursivamente. (RAGO, 2013, p. 30)

Dividiremos este artigo em três momentos, os quais estarão interligados por uma análise comparativa, pois o que justifica a escolha desse corpus é nosso entendimento de que essas mulheres comungam de um projeto comum: a "escrita de si", categoria ao quão os feminismos se inscrevem abrindo possibilidades para que as subjetividades das escritoras, em sua diversidade, sejam percebidas em seus discursos poéticos, realizados em fanzines, declamados em saraus, escritos, pintados e/ou grafitados nos muros das cidades, ou nas telas dos computadores e smartphones.

\begin{abstract}
A "escrita de si" é entendida como um cuidado de si e também como abertura para o outro, como trabalho sobre o próprio eu num contexto relacional, tendo em vista reconstituir uma estética do eu. [...] Se entendermos que os feminismos abrem possibilidades de subjetivação e de existência para as mulheres, é necessário que levemos em conta a linguagem e o discurso, meios pelos quais se organizam a dominação cultural e a resistência. (RAGO, 2013, p. 31; 50)
\end{abstract}

Nos organizaremos da seguinte forma textual: O primeiro momento Redes e conexões: uma ciranda de mulheres escritoras proposta na antologia literária e fotográfica Profundanças. O segundo momento Zine e performances, independência e autonomia nas frentes de resistências criadas por mulheres 
escritoras do coletivo Movimento Respeita!. E no terceiro e último momento Os muros da cidade dão o seu recado com a poesia de Ângela Toledo, que grafitava seus poemas nos muros da cidade turística baiana Morro de São Paulo.

\section{Redes e conexões: uma ciranda de mulheres escritoras proposta na antologia literária e fotográfica Profundanças.}

Profundanças é um projeto Organizado por Daniela Galdino, poeta e performer, oriunda de Itabuna-Ba, itinerante, a autora tem vários projetos literários, contos e poemas publicados em revistas literárias digitais, assim como em outros espaços na internet, além de participar de antologias e produções impressas. Se configurando uma antologia literária e fotográfica, Profundanças reúne diversas escritoras, algumas nunca publicadas anteriormente; outras com livros já publicados, seja por conta própria ou por meio de pequenas editoras. Daniela, como idealizadora e organizadora do projeto, vislumbrou na internet uma maneira de produzir os textos e difundi-los virtualmente de forma gratuita.

A obra se constitui numa compilação de textos e imagens de uma diversidade de escritoras, dentre elas destacamos Lílian Almeida, Aidil Araújo, Ana Mendes, Calila Das Mercês, Renailda Cazumbá, a pessoa Trans não binária JeisiEkê de Lundu, Rita Santana, Mel Andrade, dentre outras. Disponibilizado via blog e redes sociais, Profundanças 1 datada de 2014 e 02 foi disponibilizado no Ciberespaço em junho de 2017. Recentemente com sua terceira edição, o Profundanças 3, foi lançado no dia 22 de agosto de 2019.

O projeto Profundanças nos provoca o pensamento da possibilidade de ser e ter um caráter revolucionário, pois partindo da realidade de uma diversidade de mulheres, como também de pessoas Trans não binária, fatores como sexo/gênero, geração/idade, etnicidade, classe social, religião, que entram no arcabouço dos estudos Interseccionais, são levados em consideração. Profundanças 1, 2, 3 apresentam uma poesia sob rasura, contestando lugares, linguagem, signos, oportunizando momentos poéticos-performáticos, literatura itinerante, insurgente, transgressora, uma poesia que viaja, oportunizando mesas e rodas de conversa, recital e performance poética com e entre as escritoras do 
projeto literário e fotográfico. Uma poesia virtual mas também presencial. Escrita e performada.

Um projeto que se configura poético e político, de "vozes insurgentes" pois as escritoras se comprometem com/em questões sociais, debates de gênero e para além do gênero pelos estudos Queer, feminismos e o espaço da mulher na literatura e no mundo. O que retoma e desmonta de certo modo uma velha discussão da Teoria da Literatura sobre Estética e Ideologia na Literatura. Nas primeiras correntes de Teoria da Literatura a ênfase era o trabalho estético e uma certa crença de que a Literatura precisava se afastar do mundo e do contexto histórico para ser "boa literatura". Entretanto, após as discussões advindas dos Estudos Pós-estruturalistas, é possível falar de Literatura e ideologia sem classificar certas obras em meramente engajadas. Em outras palavras, o projeto Profundanças alinha-se a uma literatura que não teme seu pertencimento no mundo e não foge a seu papel ideológico.

A poesia ganha novos tons e nuances numa ciranda composto por essxs escritorxs que estão interligadx ${ }^{2}$, embora muitas ainda nem se conheçam pessoalmente, todavia, mantêm contato umas com as outrxs através das redes, destacamos aqui Facebook e Instagram. Ao passo que são escritorxs também são ativistxs, estão presentes em movimentos sociais, professoras universitárias, donas de casa, trabalhadoras autônomas, artistas plásticas, etc., todxs dando voz e corpo a uma literatura que desconcerta e desconforta.

De 2012 para cá, intimamente ligada às recentes manifestações feministas, uma nova poesia escrita por mulheres, lésbicas e trans ganha força inesperadas se amplifica com rapidez. É uma poesia diferente, que surpreende, que interpela, irrita, fala o que quer, fala o que sente, o que dói, e se faz ouvir em saraus, na web, nas ruas, enfim, onde sua palavra chega mais alto. [...] Podemos dizer, sem nenhuma hesitação, que essa geração foi responsável por trazer, de uma vez por todas, para a cena literária brasileira, a visibilidade da poesia feita por mulheres em busca de dicção própria e liberdade de expressão. (HOLLANDA, 2018, p. 105 e 106)

\footnotetext{
${ }^{2}$ Utilizamos o X indicando o não binarismo dos Estudos Queer e em respeito a JeisiEkê de Lundu, pessoa trans não binária que faz parte de Profundanças 2.
} 
As palavras de Heloísa ratificam o papel político da autoria feminina. No entanto, muitas dessas mulheres não consideravam seus textos como literários, outras já o fazia, contudo acabavam por engavetar seus textos sem cogitar a posibilidade de torná-los públicos seja por meio de publicação virtual ou impressa.

Talvez e possivelmente influenciadas pela ideia de que a Literatura durante séculos foi um espaço do masculino como nos orientava Woolf3 principalmente pela velha noção de que a boa literatura não era escrita de forma pessoal tampouco lugar para mulheres.

O projeto Profundanças oferece um grande estímulo oportunizando uma diversidade de mulheres a acreditarem em sua poética, a dar voz às suas emoções, experiências, afetos, subjetividades e ideais. "[...] levo fachos de gritos/ aonde me querem muda/ replantando-me/ dou cestos fartos" Poema arada, de Daniela Galdino. Assim também como no poema de Ana mendes: havia algo de mais escandaloso que sua voz: o peso dos próprios ombros/ a força a fé e fúria/ de seu silêncio". Ou no final do conto Fio de Silencio de Aidil Araújo

Sentiu um arrepio no corpo. Deus benza. Veio a ideia de pegar ervas de Oxum e lavar o corpo, a água escorreu desenrugando a pele, desembruçando a alma, até vontade cantar nasceu na garganta, entoou uma música antiga, que sua avó cantava para Oxum. Como é a vida - pensava enquanto descia as escadas em frente ao rio. Coseu tanto pano e a esperança estava era nas contas. Inespera o que vê. Os retratos Todos. Boiando no rio. Rapidamente sua imagem se dissolve. Deu vontade de dançar, de ser mulher tocada, de sentir coisas nunca sentidas antes. (Profundanças 2, p. 12)

Obra exclusivamente virtual e gratuita, podendo ser lida online ou off-line, onde e quando for desejada. Profundanças se configura um grande trabalho em relacionar poesia com as vivências feministas propondo rasuras e transgressões, Re-Existência por meio dos afetos, que transformam vidas e acordam almas e corações, alimentando a realização dos sonhos de muitas mulheres, o de escrever

\footnotetext{
${ }^{3}$ Woolf em Profissões para Mulheres e outros artigos femininos (2018) discutir num capítulo sobre a dificuldade masculina em reconhecer como bons os escritos das mulheres, somente como cópia do que era bom na literatura dominantemente escrita por homens.
} 
seus contos e poesias, serem lidas, vistas, suas vozes ganhando ecos pelos mundos.

No Ciberespaço e fora dele. E, portanto, contrariando, assim, a perspectiva, ainda que momentânea de Clarice Lispector, Profundanças acredita que a poesia muda o mundo, que as narrativas dessas mulheres transformam não somente suas participam de sua produção, escritorxs, fotografxs, como também daquelas que são vidas, antes transformam toda uma realidade partindo daquelas pessoas que afetadas pela poesia produzida pela interação movida pelos afetos entre as mulheres que o projeto Profundanças, sejam em leituras coletivas, saraus, recitais, mesas, seja no espaço do pessoal.

\section{Zine e performances, independência e autonomia nas frentes de resistências criadas por mulheres escritoras do coletivo Movimento Respeita!}

A Coalisão de mulheres escritoras do coletivo Respeita! surgiu a partir de um episódio ocorrido no evento do CEP 20.000, no Teatro Sérgio Porto, em novembro de 2018 na cidade do Rio de Janeiro, nessa ocasião uma das poetas para se apresentar, recitar seus poemas exigiu que um homem, um escritor e poeta famoso na época e até os dias atuais; homem este que a havia estuprado; se retirasse da sala, ou seja, o seu violentador estava presente e confortável em seu lugar de homem escritor reconhecido. Em tempo, o homem se retirou do ambiente, não sem protestos de colegas e de críticas à escritora. Todavia, permaneceu pacificamente durante todos os dias que se seguiram no evento.

Por outro lado, a poeta que sofreu represálias veladas, como relatado no Manifesto em que a Colisão se apresenta, sendo assinado por professoras acadêmicas, escritoras, poetas; dentre tantas mulheres que assinam temos: Érica Zíngano, Adelaide Ivánova, Adrienne Myrtes, Alice Ruiz, Aline Miranda, Anna Costa e Silva, Anelise Freitas, Bell Puã, Bruna Mitrano. Carla Diacov. Cristina Flores, Julia Raiz, Juliana Travassos, Katia Borges, Priscilla Menezes, Regina Azevedo, Regina Dalcastagnè e Rita Isadora Pessoa. Com o questionamento forte e cortante: 
Nós nos perguntamos: como é possível que toda mulher conheça uma outra mulher que foi estuprada, e nenhum homem conheça um homem estuprador? Como é possivel que nossos textos, que tantas vezes denunciam a misoginia, sejam celebrados por esses poetas, mas, no momento em que o acusado de estupro é um deles, se comportam como se nunca nos tivessem lido? Essa conta não fecha. Como trabalhadoras da poesia, estamos cansadas de termos nossas histórias instrumentalizadas por editores, curadores e colegas - que usam ou citam nosso trabalho para conferir preocupação e potência política a seus eventos, publicações, referenciais bibliográficos, textões de Facebook, personas públicas - sem que sejam capazes de, na hora que a vida real bate na porta, se comportarem de forma solidária e comprometida com nossa luta. O oportunismo desses homens está exposto. A brodagem está exposta. O que aconteceu no CEP 20.000 é apenas a ponta do iceberg e mostra que lutar por visibilidade não foi suficiente para transformar relações sociais sequer dentro da nossa própria categoria (que dirá fora dela!...). Lutar por visibilidade nos deu alguma melhoria no que diz respeito ao acesso a publicações e festivais, mas não nos deu direitos. Queremos mais do que visibilidade. Queremos respeito. Nós nos unimos, portanto, com o desejo de apontar uma nova direção no nosso ativismo e nas nossas demandas. Nosso posicionamento está inserido numa genealogia feminista que nos antecede, com poetas como Gilka Machado, Laura Brandão, Patrícia Galvão e muitas outras que, em fases diferentes da história, lutaram pelo Sufrágio Universal e em causas abolicionistas. As poetas brasileiras estão, há mais de um século, presentes e atuantes na luta política. (Movimento Respeita! Zine SÃO NOSSAS NOTICÍCIAS OUE DAREMOS, Goiânia, 2019)

A coalisão de poetas reúne mulheres trabalhadoras sendo jornalistas, escritoras, professoras, que procuram pensar a poesia como trabalho, e pensar o trabalho por uma ótica anticapitalista, antirracista, antipatriarcal, se constituindo um movimento poético-literário que interfere diretamente em nossa realidade social, com performances poéticas, saraus, rodas de bate-papo literário oportunizando trocas de experiências coletivas, participação em eventos informais e formais Sobre o papel da internet para o movimento feminista e o ativismo das minorias nos fala a escritora Cristiane Costa em seu artigo "Rede" para explicar o boom que a tecnologia da informação proporcionou ao movimento feminista e o ativismo das minorias sociais.

O mais comum entretanto, não é o uso das redes para a pressão democrática, como o modelo Avazz. O recurso mais utilizado pelos novos ativistas insurgentes é claramente aquele que 
privilegia a autonomia e a ação direta entre pares. Este sim é o grande poder das redes. Em seu livro Redes de Indignação e esperança: Movimentos sociais na era da internet, Manuel Castells afirma, de forma categórica, que ' a construção autônoma das redes sociais controladas e guiadas por seus usuários é a grande transformação social no século XXI. (COSTA, p. 44, In HOLLANDA, 2018)

Conscientes desse poder que se bifurca, pois que não somente o da linguagem é contestado e disputado, mas do espaço ao qual se realiza, a internet e suas redes. Independente e autônoma a fanzine SÃO NOSSAS NOTÍCIAS QUE DAREMOS, embora pareça uma publicação simples, tem artifícios tecnológicos de última geração, como poemas em código $Q R$, onde a pessoa que lê posiciona seu smartphone com o aplicativo, lendo assim o código e é levado imediatamente para um vídeo do Youtube onde as poetas Adelaide Ivánova e Erica Zíngano recitam poesias num determinado evento literário.

De 2010 para cá, intimamente ligada às recentes manifestações feministas, uma nova poesia escrita por mulheres, lésbicas e trans ganha força inesperada e se amplifica com rapidez. É uma poesia diferente, que surpreende, que interpela, irrita, fala o que quer, fala o que sente, o que dói, e se faz ouvir em saraus, na web, nas ruas, enfim, onde sua palavra chega mais alto. As poetas imprimem esse timbre em zinis, miniantologias, criam coletivos, pactuam com pequenas (grandes) editoras. (KLEIN, p. 105, In HOLLANDA, 2018)

A partir daí podemos pensar nas novas formas de narrar que essas mulheres ou esses sujeitos do(s) feminismo(s) que estão se colocando frente às elites intelectuais discursivas e sociológicas, indo de encontro às grandes mídias e editoras, como também se fazendo presente, ainda que presença incomoda, exercendo o contrapoder, ou ainda no "outro lugar", como afirma Teresa de Lauretis em seu texto Tecnologias de Gênero, reeditado recentemente por Heloisa Buarque de Hollanda em Pensamento Feminista. Conceitos Fundamentais

A razão pela qual a crítica de todos os discursos a respeito do gênero [...] continua a ser uma parte tão vital do feminismo quanto o atual esforço para criar novos espaços de discurso, reescrever narrativas culturais e definir os termos de outra perspectiva- uma visão de "outro lugar". [...] Pois esse outro lugar não é um distante mítico passado, nem a história de um futuro utópico: é o outro lugar do discurso aqui e agora, os pontos cegos, ou o space-off [...]. Eu o imagino como espaços nas margens dos discursos hegemônicos, espaços sociais 
entalhados nos interstícios das instituições e nas fendas e brechas dos aparelhos de poder-conhecimento [...] nas práticas micropolíticas da vida diária e da s resistências cotidianas que proporcionam agenciamento e fontes de poder ou investimento de poder; e nas produções culturais das mulheres, feministas, que inscrevem o movimento dentro e fora da ideologia, cruzando e recruzando as fronteiras- e os limites- da(s) diferença(s) sexual(ais). (LAURETIS, p.150, In: HOLLANDA, 2019)

Dialogando com Lauretis encontramos em van Dijk no seu livro Discurso e Poder (2017), precisamente no capítulo "Estruturas do discurso e estruturas de poder" sua afirmação sobre as elites de poder e como estas podem controlar e manobrar os discursos, assim como legitimar ou deslegitima-los. Podem, também, desvirtuar um discurso, descaracterizando-o para sua não aceitação ou a manipulação a fim da internalização de um discurso para a discriminação das massas.

\footnotetext{
As elites intelectuais também possuem acesso a manobras para controlar a dissidência e a resistência [...] propondo formas mais ou menos confessas de censura, recorrendo a campanhas de difamação e outros mecanismos para silenciar [...] por isso em muitos países ocidentais, basta que alguém seja taxado como "comunista", ou como pessoa contrária ao nosso tipo de "liberdade" ou a um valor dominante similar, para ser desqualificado como formulador serio de contraideologias. (DIJK, 2017, p. 51)
}

Conscientes do momento político atual em que vivemos o Movimento de poetas Respeita! aparece questionando e chamando para a reflexão, usando das tecnologias narrativas para se contrapor as violências de gênero, desconstruções, ressignificações para além do gênero- inscrito no manifesto do movimento; assim como para a opressão, silenciamento e criminalização dos movimentos sociais. Mulheres intelectuais, não necessariamente acadêmicas, todavia mulheres engajadas em movimentos sociais, leitoras, estudiosas, pesquisadoras que não se deixam intimidar pelo sistema normativo, hegemônico e capitalista muito menos pelo patriarcado, ou misoginia e a violência contra às mulheres, antes utilizam de seus conhecimentos para a subversão, principalmente da linguagem, da criação, da performance poética e soltam seu grito de denúncia, de alerta, desejando e 
trabalhando para alcançar o maior número de pessoas, seja nas redes, seja nas ruas.

A poética desses textos ratifica o debate da $A C D$ na qual as estruturas do discurso são imbricadas a estrutura do poder. As autoras sabem que os modos como escrevem, rasurando a linguagem normativa (seja por reinventar e refazer palavras) utilizando-se de novos meios (internet) são ações políticas cuja prática discursiva tem a intenção de modificar a prática social. O que tem acontecido com certa maestria e nenhuma ingenuidade. Pois essas mulheres, munidas de conhecimento formal e informal, de leituras canônicas e para além do cânone, festejam suas vozes como gritos que por tanto tempo foram abafadas, diminuídas, apagadas.

\begin{abstract}
A tendência de eliminar marcadores explícitos de poder está intimamente ligada à tendência à informalidade: é nos tipos mais formais de situações que as assimetrias de poder e status são a mais nítidas. Uma manifestação central de informalidade crescente é a forma com que o discurso conversacional tem sido e está sendo projetado de seu domínio primário, nas interações pessoais da esfera privada para a esfera pública. [...] Isso é parte de uma reestruturação importante dos limites entre os domínios públicos e privados. " (FAIRCLOUGH, p. 261)
\end{abstract}

Nesta passagem de Fairclough em Discurso e Mudança Social (2016) impossível não lembrar da bandeira feminista "o pessoal é político". Mais do que um mero jargão, essa declaração abalou as certezas do pensamento científico, pois desautorizou uma série de dicotomias a ela associadas: público (masculino); privado (feminino); Masculino (razão); Feminino (emoção) e tantas outras.

Desautorizada a supremacia do público sobre o privado outros projetos de dizer-se foram também de certo modo possíveis. Fazemos aqui um paralelo entre o significativo propósito da categoria Escrevivência (2016) de Conceição Evaristo e as escritas de si de Margareth Rago em A aventura de contar-se (2013) As autoras teorizam sobre os processos linguísticos do discurso que aproximando discurso da linguagem falada, ou da linguagem mais informal, não somente pelo modo como é escrita, mas, sobretudo como essa escrita se realiza. O tom intimista, de dentro para fora, onde o limite de fora para dentro já não se pode ver com tanta nitidez. Esse estilo de fala-escrita já foi sinalizado em muitas escritoras Brasileiras (BARBOSA, 2011, p.76) 
Este artificio pode não ter sido calculadamente pensado pelas primeiras mulheres escritoras brasileiras, como Carolina de Jesus, contudo, tem se transformado num potente instrumento de aproximação entre quem lê e quem escreve, de modo semelhante ao Profundanças estimulando a voz daquelas mulheres que desacreditavam que não tinham o direito ao discurso, à escrita. Vemos o território discursivo travando embates ideológicos, que não estão somente no plano das ideias, antes e muito no campo das ações. Como nos chama atenção a escritora Priscilla Menezes no poema a seguir.

Eu estou me cuidando e isso tem a ver com andar por onde não deveria. Tanta coisa desmorona, mas não o que, em sua queda, abriria espaço para mais formas de vida. O desejo é uma força assustadora. Enquanto pudermos desejar, seremos a constante possibilidade de uma bomba rente ao estado das coisas. Eu te desejo muita fúria. Eu desejo que nossas águas se encontrem, formem correnteza e vinguem a memória de todos os rios aqui soterrados. A terra vive e conspira e nós também. Nossas águas poderiam condenar todas as estruturas desse mundo erguido pelos homens. A umidade traria tudo abaixo e teríamos que, uma vez mais, olhar para a terra, onde temos aliados. O que queima, o que enfrenta, o que não cessa de retornar. O estado aquoso da matéria, que, multiforme, escapa e avança. Isso há fora e dentro de nós e constitui um manancial que assombra a firmeza de toda a pátria. Disso eles sabem muito pouco. Isso eu falo nos vãos, em becos, nas ruelas. Para que faça ecos e também eu escute. Que escorra. " (Zine SÃO NOSSAS NOTÍCIAS QUE DAREMOS, 2019, P.34)

A coalisão de mulheres do Movimento Respeita! tem articulado suas ações políticas e ideológicas por meio de seus discursos, de suas poesias, seus recitais, escrita manifesto, como o nome da fanzine anuncia, feito jornal lançado para o mundo SÃO AS NOTÍCIAS QUE DAREMOS4. A poesia denúncia, buscando incessantemente a mudança e transformação social por meio do discurso literário, que se caracteriza, segundo DIJK (2017) uma forma de poder. E aqui, um contrapoder promovido por mulheres, dialogando com o FEMINISMO para os 99\%, UM MANIFESTO (2019), manifesto esse que fala sobre um feminismo em

\footnotetext{
${ }^{4}$ As letras escritas em caixa alta no espaço do virtual significa que a pessoa ao digitar esteja gritando. O movimento RESPEITA! Utiliza-se desse artifício para dar o seu grito, chamar atenção para sua escrita, narrativas, SÃO NOSSAS AS NOTICIAS OUE DAREMOS.
} 
que caiba todos os feminismos, todas as mulheres, de maneira interseccional, atentando, sobretudo, para o Capitalismo e suas formas de opressão.

\section{Os muros da cidade dão o seu recado: A resistência poética de Ângela Toledo e seu legado em Morro de São Paulo.}

O nosso olhar para a poética de Ângela Toledo será diacrônico, vista pela ótica da pesquisadora Adriana Maria de Abreu Barbosa, no artigo de sua autoria ano de 2015, "GRAFITES POEMAS DE ÂNGELA TOLEDO" (2017), fazendo parte do livro CAMINHOS da VIOLÊNCIA em busca da VISÃO COMPARTILHADA. INTERPRETAÇÃO E COMENTÁRIO DE TEXTOS DE AUTORIA FEMININA organizado por Helena Parente Cunha. Veremos a poética de Ângela Toledo dos tempos de 2013 e 21014 e como se faz presente nos dias atuais.

Numa narrativa fluente a pesquisadora Adriana Abreu conta-nos, de modo a nos aproximar como se estivéssemos em sua companhia na viagem ao conhecimento e encontro com "o ativismo sociocultural" Ângela Toledo, em suas duas viagens feitas

à cidade turística Morro de São Paulo, na Bahia, nos anos de 2013 e 2014. Adriana relata que passeou pelas ruas com um olhar flâuner e a consciência de pesquisadora, a flertar com a atmosfera do lugar, conversar com comerciantes, onde via a oportunidade de perguntar sobre a poeta e ouvir acerca de características empáticas e de seus esforços para registar sua poesia nos muros da cidade turística, onde o consumismo é algo altamente explorado, seus poemas-grafites com temas sobre a valorização da vida na natureza, da simplicidade, a partir deste fato a pesquisadora encontra uma ponte com o Ecofeminismo, se configurando assim, numa "forma alternativa de resistir e existir" (2015) à realidade marginalizada da comunidade de Cairu-Ba.

Como Milton santos (2013), temos esperanças nas interrupções contra a perversidade do mundo globalizado por meio de novas ações, novas relações e novas ideias. Portanto, abraçamos o projeto Muro que Fala, de Ângela Toledo, por reconhecer nele um potencial para mudança: uma saída de um mundo excludente, violento e perverso em direção a um mundo de mais dignidade. Sendo assim. Gostaríamos de dar a ele, projeto, e a ela, poetisa, a visibilidade que merecem. (BARBOSA, p. 27) 
A poeta pintava os muros com seus próprios recursos e a ajuda de comerciantes locais, assim como participava da feira artesanal de Morro de São Paulo com seus livros artesanais de poemas, produzidos manualmente. Os muros recebiam novos poemas de tempos em tempos, nova grafitagem. Somente no ano de 2014 que a prefeitura pagou as tintas para que Ângela, junto com as crianças da comunidade do distrito de Cairu, pudessem avivar os caminhos daquele ponto turístico que leva o nome de uma grande metrópole brasileira, recebendo pessoas de todos os lugares do mundo.

Assim também a descreve Adriana Barbosa "Ângela Toledo com identidade hibrida" (BARBOSA, 2015) pela poeta que ao passo que almejava pertencer ao mundo inteiro, sendo de qualquer parte e ao mesmo tempo sendo de lugar algum, amando o momento e o estar de agora, falava de lugares simbólicos como se estivesse em todos ao mesmo tempo como no poema "A praça":

A praça

Amo essa praça cheia de graça

Amor de "Vinícius". Amor de "Castro Alves"

Nem Copacabana amei assim, A praça das mães muito me comove; Mas é essa pequena e singela praça,

Que me faz feliz. (Quase poesia)

Matéria prima de muitos de seus escritos, a maternidade toma conta dos holofotes quando se trata da "mãe de verdade", daquela mulher que gera, uma crítica também a da sociedade patriarcal que valoriza a mulher somente quando essa pode parir. E sendo a maternidade símbolo, o abandono das crianças nascidas também era tema, possivelmente, pelo grande número de crianças com quem trabalhava em projetos de incentivo à cultura em oficinas de pintura. Como vemos num poema que pela sua força discursiva, pelo seu potencial político, grita ao passo que nos cala, num silêncio cheio de vozes sobre o abismo da maternidade compulsório e da orfandade que a sociedade busca esconder.

É

Bom

Que

A

Mulher

Eutomia, Recife, 26(1): 414-434, Dez. 2020 
Pare

De

Parir

Até

Que

Cada

Criança

Tenha

Uma

Mãe (Ângela Toledo. In: Quase poesia)

Com elementos do Feminismo da Diferença, Ecofeminismo, de um Existencialismo espiritualizado a pesquisadora Adriana Barbosa desenvolve o seu enredo sobre a poeta que resiste e insiste na transformação por meio da poesia. Ângela foi uma mulher que utilizava a literatura, a poesia como instrumento de resistência, vendo nos muros da cidade oportunidade de atingir o maior número de pessoas possível, aquelas que não liam seus livros, turistas com seus tantos motivos para estar naquele "lugar de descanso", aproveitando a oportunidade para rasurar os espaços estabelecidos socialmente.

O questionamento sobre o lugar ocupado pelos grafitespoemas da artista ganha adensamento à medida que estabeleceu o que nos orienta Canclini sobre a normatização moderna que estabeleceu lugares para o consumo de coisas diversas [...] Desse modo, a cultura moderna, a organizar lugares, também prescreve modos de olhar cenários. (BARBOSA, p. 25)

Ângela Toledo foi uma poeta que não somente interferia na realidade com a pintura nos muros, como também foi a fundadora da AMOSP (Associação de Artistas e Artesão Moradores do morro de São Paulo, onde buscava mobilizar os/as artistas locais para uma conscientização e humanização de estar naquele espaço e poder interferir com o trabalho que realizavam. A última notícia que tivemos da AMOSP foi em 26 de abril de 2019, uma pequena nota num jornal virtual contando da $5^{a}$ Mostra de Artesanato e Cultura, realizada pelo Seabra, Instituto do Patrimônio Artístico e Cultural da Bahia (Ipac), Secretaria do Trabalho, Emprego, Renda e Esporte (Setre) e o empresariado local juntamente com a Prefeitura de Cairu por meio da Secretaria de Cultura do município. ${ }^{5}$ Nos

\footnotetext{
${ }^{5} \mathrm{~A}$ informação pode ser encontrada no endereço eletrônico: https://valencaagora.com/morro-desao-paulo-sedia-5a-mostra-de-artesanato-e-cultura/.
} 
pareceu foi que, após a morte de Ângela, o trabalho em torno do ativismo sociopolítico cultural foi se dissipando dando lugar ao artesanato pela sobrevivência.

A obra de Ângela pode não mais estar nos muros da cidade, falando ainda que no silêncio, mas está registrada em artigos, para que a sua história e luta social não sejam apagadas. Em vida, Ângela lutava por uma comunidade invisibilizada, seus poemas-grafites ou seus livros artesanais de poesia tratavam de questões globais e locais, na esperança de mudança, de uma transformação não somente para os seus, como também para todos que aqueles pudessem ter acesso ao seu discurso poético.

Agora

é hora de deixar ir

este fardo, de deixar de lado

o que não for amor.

Agora

é hora de sair por aí

com os pelos eriçados

Coração acelerado e o

peito em flor.

Assim, Ângela Toledo foi uma poeta que rompeu com o silêncio, a indiferença e abismo social por meio de seus grafites-poemas, alcançando lugares-pessoas que não podemos estimar, contudo, estarmos certas de que estivemos diante de um grande momento histórico onde uma mulher movimentou uma comunidade a fim de transformá-la. Tomá-la mais humana e menos desigual para além de suas fronteiras.

\section{Inconclusões do Re-existir}

Um grande ponto em comum entre essas mulheres que avançam e avançaram num território contestado é a ação de autogestão e transgressão, pois são elas mesmas que fazem e fizeram, produzem sua literatura e são responsáveis pela sua, publicam e publicaram seus próprios livros, sejam artesanalmente ou virtualmente ou por meio das pequenas editoras- que não por acaso são também 
formadas por uma reunião de escritoras. Gestoras de si, independentes e autônomas.

Ângela Toledo deixou e deixa seu legado não somente na memória e nos textos escritos por ela e sobre ela, como também a continuação do trabalho das mulheres que do movimento RESPEITA! com seus zines artesanais, ou o Projeto Profundanças com suas publicações virtuais e gratuitas para download, não dependendo de editoras para julgar se seus trabalhos são ou não suficientemente dignos de seres publicados e vendidos, ultrapassando a censura e o veto das elites intelectuais descritas por Van Dijk (2017), rompendo, assim, com o silenciamento e o apagamento das mulheres na história atual.

Em seu artigo intitulado Centro e margens: notas sobre a historiografia literária de Rita Terezinha Shmidht coloca a importância de se ter uma literatura voltada para as questões sócio culturais e humanas, a dificuldade da Teoria da Literatura e dos Estudos Literários em alcançar ou aceitar poéticas para além do cânone

Penso que os estudos literários podem articular o seu papel educacional com a função social de relevância na medida em que abrirem o campo de reflexões e crítica às fronteiras de silenciamento, de exploração e destituição do humano. Mas isso só se tornará possível mediante decisões de caráter ético, estético e político com vistas à construção de um pensamento diferencial que possa deslocar o universalismo abstrato construído pelas subjetividades engendradas pela hegemonia da história única, seja a do passado nacional, seja a da aldeia globalizada. Nessa linha, o papel de uma nova história da literatura viria ao encontro da necessária reeducação das capacidades de discernimento, da sensibilidade e do respeito incondicional à alteridade, capa idade necessárias à formação de competências de viver com as quais poderíamos reivindicar o passado, e consequentemente, a nós mesmos. Não pode ser outro, senão, o compromisso diante do que significa existir no presente. (SCHMIDHT, p. 39 e 40. In: Literatura e Exclusão, EBLEL \& DALCASTAGNË, 2017)

Como resposta à reflexão de Schmidht e a nossa curiosidade sobre a estratégias do fazer poético e das estratégias discursivas das mulheres escritoras que este artigo tomou forma, procuramos mostrar três momentos diferentes de mulheres escritoras, muitas que viveram à margem por um grande espaço de tempo, tendo que alcançar espaços de poder, como a educação formal em seus 
níveis mais elevados, adentrar à academia, terminar uma graduação, realizar um mestrado, doutorado, etc., para também disputar um dos espaços mais fortes e sutis que é a linguagem.

As narrativas subversivas como tecnologias sendo produzidas em forma de discurso, discurso sendo ouvido, lido, pintado, se realizando literariamente, alcançando espaços onde outras ciências e saberes não chegam como afirmou a socióloga Patrícia Hill Collins numa entrevista à Suplemento Pernambucano (2018) em sua vinda à Flica em 2018,

\begin{abstract}
A literatura atua na medida em que lemos histórias dos outros e contamos nossas próprias histórias. Se você está firme do seu lugar, você pode se conectar com outros. Para mim, ações e ideias caminham juntas. Assim penso que a literatura pode fazer, em termos de ativismo, o que nenhuma cientista social do mundo pode fazer. (SUPLEMENTO, p. 9, 2018)
\end{abstract}

Assim, a literatura chega as periferias das grandes e pequenas cidades, como aconteceu com o trabalho realizado pela poeta Ângela Toledo na comunidade pobre de Cairu (Morro de São Paulo-Ba). Ou pelas redes sociais com - Movimento RESPEITA! com seus artifícios tecnológicos e sua publicação internacional; e o projeto fotográfico e Literário PROFUNDANÇAS, que leva poesia para às escolas da Bahia e de outros estados, para as universidades, os espaços acadêmicos e não acadêmicos.

Por acreditar nessa literatura escrita por mulheres feministas que buscam Re-existir, construindo e reconstruindo novas maneiras de estar no mundo, que nos faz acreditar que através da arte, de uma literatura que reflete, denuncia, cria, pensa, diverte, a literatura atua como agente transformador em nossa sociedade. A linguagem que se transforma em discurso, narrativas se realizando em suas muitas faces, facetas, maneiras, construímos realidades possíveis para não somente sobrevivermos, antes vivermos e criarmos com dignidade e esperança. A Literatura tendo a capacidade de contar a história a seu modo, não necessariamente como mentira ou invenção, antes sob uma outra ótica e perspectiva, e porque não por uma epistemologia própria?

\title{
Referências Bibliográficas
}


AMORMINO, Luciana. Identidade e memória: um olhar a partir dos Estudos Culturais. Revista do Programa de Pós-graduação em Comunicação Universidade Federal de Juiz de Fora / UFJFVol.1, n² 2, Dezembro 2007, em: www.ppgcomufjf.bem-vindo.net/lumina.

BARBOSA, Adriana Maria de Abreu. Ficções do Feminino. Vitória da Conquista: Edições UESB, 2011.

BARBOSA, Adriana Maria de Abreu. GRAFITES POEMAS DE ANGÊLA. Caminhos da violência em busca da visão compartilhada: interpretação e comentários de textos de autoria feminina, cap. I. Rio de Janeiro: Letra Capital, 2015.

BRITTO, Milena. Afetar a cena literária: política, afinidade, estratégias e autogestão entre os autores contemporâneos. Org.: AZEVEDO, Luciene \& PEREIRA, Antonio Marcos. Palavras da Crítica Contemporânea. Boto-cor-de-rosa livros, arte e café/paralelo13S. $1^{\text {a }}$ Ed.- Salvador, 2017.

DALCASTAGNĖ, Regina. Literatura brasileira contemporânea, um território contestado. Vinhedo, Editora Horizonte, 2012.

DALCASTAGNĖ, Regina. EBLE, Letícia Jensen. Literatura e Exclusão. Porto Alegre- RS: Editora Zouk, 2017.

DALCASTAGNE, Regina; LICARÃO, Bertoni; NAKAGOME, Patricia. Literatura e Resistência. Porto Alegre- RS: Editora Zouk, 2018.

DUARTE, Constância Lima Duarte; CORTÊS, Cristiane e PEREIRA, Maria do Rosário A. (Org.) Escrevivências: identidade, gênero e violência na obra de Conceição Evaristo. Malê edições, 2016.

DIJK, Teun A. van. Discurso e Poder. 2.ed. São Paulo: Contexto, 2017.

FAIRCLOUGH, Norman. Discurso e Mudança Social. Brasília: UnB, 2001.

GALDINO, Daniele. Profundanças: antologia literária e fotográfica / Daniela Galdino (org.). $1^{\text {a }}$ edição. Ipiáu, BA: Voo Audiovisual, 2014.

GALDINO, Daniele. Profundanças 2. Ipiaú: Voo Audiovisual, 2017.

HOLLANDA, Heloísa Buarque (Org). Tendências e impasses. Feminismo como crítica da cultura. Rio de Janeiro: Rocco, 1994.

HOLLANDA, Heloísa Buarque (Org). Explosão Feminista: Arte, Cultura, Política e Universidade. $1^{\text {a }}$ ed. São Paulo: Companhia das Letras, 2018. 
HOLLANDA, Heloísa Buarque (Org). Pensamento Feminista: conceitos fundamentais. Rio de Janeiro: Bazar do Tempo, 2019.

RAGO, Margareth. A Aventura de Contar-Se: Feminismos, Escrita de si e Invenções da Subjetividade. Editora da Unicamp; Edição: 1, 2013.

RESPEITA!, Movimento. Zine SÃO NOSSAS NOTICÍCIAS QUE DAREMOS, Goiânia, 2019

GÓIS, Edma de. LUNA, Danielle de. Literatura e ativismos para segurar o mundo. Revista Suplemento Pernambucano, n 153. Editora CEPE: Pernambuco, 2018.

\footnotetext{
'Allinne Silva Possui graduação em Letras Vernáculas com habilitação em Língua Portuguesa e suas Literaturas, pela Universidade Estadual do Sudoeste da Bahia- campus de Jequié. (2009). Especialização em Libras pela Universidade Candido Mendes. (ESPG) - MG. Mestra em Relações Étnicas e Contemporaneidade. PPGREC/UESB, Jequié-Ba. Pesquisa a Literatura de autoria feminina na contemporaneidade com a perspectiva teórica dos Estudos Interseccionais, Análise Crítica do Discurso e Crítica Feminista.

ii Adriana Maria Barbosa é Graduada em Letras pela UERJ (1992), Mestre em Língua Portuguesa pela PUC do Rio (1996) e Doutora em Semiologia pela UFRJ (2001). Pós-doutora pelo Programa de Pós -graduação em Letras da UFPE (2015). Professora Titular da Cadeira de Teoria da Literatura no Departamento de Ciências Humanas e Letras (DCHL) da UESB; Coordenadora do Grupo de Pesquisa GETED (Grupo de Estudos em Teorias do Discurso); Professora no Programa de Pós-graduação em Letras: Cultura, Educação e Linguagem (PPGCEL_UESB). Atua na docência de Teoria Literária. Pesquisa a literatura de autoria feminina na literatura brasileira moderna e contemporânea, com o viés da Crítica Feminista.
} 